\title{
Balance of Oppositions as a Philosophical Base of Maximilian Voloshin's Life and Creativity
}

\author{
Pinaev Sergey Michailovich ${ }^{1}$
}

Professor of Russian Peoples' Friendship University, Moscow, Russia.

(date of receiving: April, 2019; date of acceptance: November, 2019)

\begin{abstract}
The article deals with the main characteristic of the worldview and creativity of M.A. Voloshin is about the harmony of his world as a balance of opposites. This principle is supposed to work at all levels of being. First, it is given in the personality of the poet: as the width of his soul and spiritual infinity on one hand and the discipline and selfrestriction on the other. In the totality of the world there are the oppositions of God and devil and the opposition of two devils as making the balance of the whole world. The world itself as a system of strong balances. In history there are two streams of time, "flowering and break-up". When the balance is disrupted the catastrophe happens, and this is obvious in Russian Revolution. But Voloshin believes that the process of destruction is limited and opposed by the principle of Love.
\end{abstract}

Keywords: Voloshin, World Outlook, Harmony, Balance, Oppositions, Revolution.

1. E-mail: serpinaev@mail.ru 


\title{
Система равновесий как философская основа жизни и творчества Максимилиана Волошина
}

\author{
Пинаев Сергей Михайлович ${ }^{1}$ \\ Профессор, Российский университет дружбы народов, \\ Москва, Россия. \\ (дата получения: апрель 2019 г.; дата принятия: ноябрь 2019 г.)
}

\begin{abstract}
Аннотация
В статье речь идет об основной характеристике мировосприятия и творчества М.А. Волошина - о гармоничности его мира как равновесии противоположностей. Этот принцип последовательно полагается им на всех уровнях бытия. Прежде всего, он проявлен в самой личности поэта: как многогранность личности и духовная безмерность, с одной стороны, и дисциплина и самоограничение, с другой. В строении мироздания это противоположности сил: Бог - дьявол, два демона как уравновешивающие друг друга силы; сам мир как «мир осязаемых и стойких равновесий»; в истории - «двойная бесконечность» времени, два потока цветение и распад. Нарушение равновесия, что характерно для революций, приводит к катастрофическим последствиям, но распаду, по Волошину, противостоит принцип любви.
\end{abstract}

Ключевые слова: Волошин, Мировосприятие, Гармония, Равновесие, Противоположности, Революция.

1. E-mail: serpinaev@mail.ru 


\section{Введение}

Жизнь и творчество Максимилиана Волошина представляют собой цельный феномен, для понимания которого важно выявить его философскую основу, мировоззрение поэта - как оно, прежде всего, проявляется в его стихотворениях. В настоящее время в волошиноведении эта тема - одна из самых значимых, и при этом дискуссионных. Думается, что прежде чем характеризовать мировоззрение поэта, его нужно описать, основываясь на тщательном анализе его произведений. И, прежде всего, раскрыть такие слова, как «гармония», «гармоничность», которые постоянно употребляются исследователями. Действительно, Волошин ищет и находит - в лирическом самовыражении, в природе, в мироздании, - как писала близко знавшая поэта Марина Цветаева, то единство, в котором было всё, и то всё, которое было единством. Целокупность многообразия - это в целом главная особенность волошинского творчества. Она прослеживается как закономерность на различных уровнях бытия, отраженного в волошинском творчестве: в личности самого поэта, в его понимании основ мироздания и строя космоса, в восприятии им человеческой истории и истории России. При этом в воссозданном Волошиным мире нарушение равновесия между противоположными полюсами этих многоплановых целокупностей всякий раз проявляется в катастрофических последствиях.

\section{Основная часть}

Оставаясь глубоко русским поэтом, преклоняясь перед Пушкиным и Достоевским, Тютчевым и Вл. Соловьёвым, Волошин вбирал в себя культуру Запада и Востока, объединяя элементы той и другой культур в своём творчестве. Творчество это невозможно воспринимать исключительно с какойто одной религиозной или философской позиции, будь то христианство, антропософия, масонство или что-то ещё. Как поэт и мыслитель Волошин не 
укладывается ни в одну конкретную эстетическую систему или эзотерическую концепцию. Он как личность, с его творчеством, его стихи и проза, выше и шире любой однополярности в мировоззрении: это «средоточье всех путей»литературы, культуры, философии - в России Серебряного века, некое всеобъемлющее единство, в котором тесно спаяны поэзия, эссеистика, живопись, соединены традиции и яркая индивидуальность. «...Так нельзя выломать отдельные завитки из ракушки... её очарование - целое», - писал Андрей Белый, подметивший это «целое» в крымском доме Волошина: «Дом Волошина, начиная с внешних форм до музейных остатков быта этой творческой жизни, восхищает меня как одна из ракушек, которыми мы любуемся...» (Воспоминания о Максимилиане Волошине 1990. 507), - как, впрочем, и в его творчестве: «целое единственной жизни; поэт-Волошин, Волошин-художник, Волошин-парижанин, Волошин-коктебельский мудрец, отшельник и краевед даны в Волошине, творце быта...». Можно принимать или не принимать Волошина во всех этих ипостасях, но необходимо выделить главное, доминанту личности, подмеченную Андреем Белым: «...во всех согласиях и несогласиях меня пленяли» в нём «широта интересов, пытливость ума, многосторонняя начитанность, умение выслушать собеседника и удивительно мягкий подход к человеку», его способность выступать в роли «миротворца, сглаживая противоречия между противниками, часто не видящими из-за деревьев леса...» (Воспоминания о Максимилиане Волошине 1990. 508).

«Француз культурой, русский душой и словом, германец - духом и кровью» (Воспоминания о Максимилиане Волошине 1990. 262) - так определила составляющие творческой личности Волошина М. И. Цветаева, связывая с «германством Макса» его пантеизм («всебожественность, всебожие, всюдубожие»), вбирающий в себя весь окружающий мир с населяющими его людьми, далёкими и близкими, а также мистицизм 
(«родники скрытые из скрытых и тайные из тайных»). Если французская культура прививала Волошину дисциплину художественной формы, обогащала палитру его изобразительных приёмов, то славяно-германская «безмерность духа» пронизывала волошинское творчество изнутри, способствовала рождению философских и эзотерических концепций, вела к постижению мира как «открытой книги», которую, прочитывая, человек принимает в себя. Отсюда - характерный волошинский тезис: «Человек - это книга, в которую записана история мира». Этот тезис мы находим среди его записей за 1907 год.

Однако «безмерность духа» требует сдерживающей формы. Поэтому обратной стороной данного принципа является закон самоограничения, наличие некоей сдерживающей силы, контролирующей и направляющей работу духа. В стихотворении «Подмастерье» (1917), представляющем собой для Волошина поэтический символ веры, читаем: «Для ремесла и духа единый путь: / Ограниченье себя...» (Волошин 2003. 216) - строки, являющиеся разработкой гётеанского мотива: «Лишь в чувстве меры мастерство приметно, / И лишь закон свободе даст главенство» («Природа и искусство», 1800). Самопознание личности поэта начинается с самоограничения и самодисциплины, с выработки устойчивых жизненных принципов, что окажется для Волошина особенно ценным в период лихолетья. Волошин сводит эту тему самоограничения к афористически выраженному императиву в стихотворении «Подмастерье», говоря о творческом процессе: «Стих создают - безвыходность, необходимость, сжатость, Сосредоточенность...» (Волошин 2003. 216). Для поэта «безвыходность, необходимость, сжатость» - это закон, имеющий отношение не только к художественной форме, но и к жизненному коду поведения. «Все трепеты и все сиянья жизни» (Там же. 217) могут быть почти сведены на нет, дух поэта отрешается от трепетов жизни, и они лишь в снятой и скрытой форме могут 
мерцать в глубине слов - ради совершения подвига творчества, ведь оно подчинено законам духа и «является неугасимым горением совести» (Волошин 1988. 301).

Совесть - одно из ключевых слов в нравственной и философской системе Волошина. Отмечает он и в поэме «Россия», говоря о природе русской натуры, это «бродило духа - совесть / И наш великий покаянный дар...» (Волошин 2003. 379) - нечто родственное утверждению С.А. Аскольдова о «соборной целостности русской души» и о том, что в России «всегда осуществлялся подвиг братского замещения греха одних смирением, терпением других» (Из глубины 1991. 32). И, конечно, молитвой. Молитва «за тех и за других»- это единственное, что в годину братоубийственной войны оставалось поэту, выучившемуся «молиться за палачей», ибо, как он писал, «каждый / Есть пленный ангел в дьявольской личине». Это свое знание он выражает в стихотворении «Потомкам», с его острыми противоположностями, соединенными в единство: «На дне темниц мы выносили силу // Неодолимую любви, и в пытках // Мы выучились верить и молиться // За палачей, мы поняли, что каждый // Есть пленный ангел в дьявольской личине...» (Волошин 2003. 350). Именно отсюда вытекает его способность видеть и в белом офицере, и в красном комиссаре - братьев.

«...Когда дети единой матери убивают друг друга, надо быть с матерью, а не с одним из братьев». А братья равны в своей правоте и неправоте. Волошин был убеждён, что мир строится на равновесиях. «Две дуги одного свода, падая одна на другую, образуют несокрушимый упор. Две правды, два принципа, две партии, противопоставленные друг другу в устойчивом равновесии, дают опору для всего здания» (Волошин 1992. 81).

Мысль о равновесии двух сил, созидающих мироздание, была высказана поэтом ещё в сонетном мини-цикле «Два демона» $(1911,1915)$. Это два сонета, объединённых по принципу контрапункта, двуединства антиномии. Первый 
Демон олицетворяет тлетворность цивилизации, убийственный дух механикорационалистического начала: «Я друг свобод. Создатель педагогик. / Я инженер, теолог, физик, логик. / Я призрак истин сплавил в стройный бред» (Волошин 2003. 201). Наука в данном случае воспринимается поэтом односторонне-негативно, разум и прогресс - в их антигуманной функции. Рационалистическое начало в современном мире, как считает Волошин, легко подменяется одурманиванием, «наркозом» учений, что ведёт к видимости политических свобод, ложной гармонии и «общедоступному» счастью. Если первый Демон, «князь земли» (Волошин 2003. 201), в чём-то сродни Мефистофелю, то его антипод, второй Демон, заключает в себе мильтоновскую традицию. Это падший ангел, Богоборец, олицетворяющий творческое начало жизни («Мятежный дух, ослушник высшей воли» (Там же.) с его противоположностями: «Я свят грехом. Я смертью жив. В темнице / Свободен я. Бессилием - могуч. / Лишённый крыл, в паренье равен птице...» (Там же. 202). Возможно, в этом сонете сказалось увлечение Волошина масонством. Однако второй Демон, хоть он и ближе автору, не отстраняет первого. Это две стороны единого целого.

Исходя из тех же принципов, оценивает Волошин и историю. Он прокламирует, прежде всего, единство движения по времени вперёд и назад. Но такое движение, в сущности, оказывается отсутствием движения. Так, ничего не меняется вследствие взаимодействия классов, правящего и уголовного, которые во время революции, по мнению поэта, только меняются местами. Ничего не меняется и тогда, когда современность неожиданно «наплывает» на, казалось бы, ушедшие эпохи, которые вдруг «выныривают» из бездны времён. На первый взгляд, здесь возникают ассоциации с тезисом Б. П. Вышеславцева, который утверждал, что «история идёт в обе стороны, к началу и к концу, что она всегда “архаична" и телеологична, что смысл изучения истории состоит не в созерцании прошлого, а в предвидении 
будущего...» (Вышеславцев б.г., 118). Вероятно, Волошин согласился бы здесь с понятием телеологичности, заданности истории. Но Вышеславцев имеет в виду взаимообратное движение по времени, историческому времени. В случае же с Волошиным речь может идти не столько об историческом, сколько о мифологическом времени.

В мифологическом времени отсутствуют начало и конец: к нему не применимо понятие линейной протяжённости. У Волошина в первом же программном четверостишии 1902 года, задающем тон всему творчеству («И мир как море пред зарёю, / И я иду по лону вод, / И подо мной и надо мною / Трепещет звездный небосвод...» (Волошин 2003. 11)), лирического героя окружает время без границ, без начала и конца - он как бы вписан в вечность. В стихотворном «Письме», обращенном к Маргарите Сабашниковой, поэт говорит о своём мироощущении такими словами: «...Но мне понятна беспредельность, / Я в мире знаю только цельность...» (Волошин 2003. 55). Волошин уподобляет поэтов перешагнувшим через время «мудрым и бессмертным» кентаврам, в которых заключены «бег планет и мысль Земли» (Волошин 2003. 56). В стихотворениях из цикла «Когда время останавливается» (1903-1905) этот ракурс мировидения ещё более ощутим: «И день и ночь шумит угрюмо, / И день и ночь на берегу / Я бесконечность стерегу / Средь свиста, грохота и шума. / Когда ж зеркальность тишины / Сулит обманную беспечность, / Сквозит двойная бесконечность / Из отражённой глубины» (Там же. 39)

«Двойная бесконечность», простирающаяся в обе стороны... Эта амбивалентность мироощущения, осознание себя в мгновении и вечности, создаёт силовое поле стихов: «Быть заключённым в темнице мгновенья, / Мчаться в потоке струящихся дней. / В прошлом разомкнуты древние звенья, / В будущем смутные лики теней...» (Волошин 2003. 38). Сам временной поток осознаётся в мифологии как нечто цельное («Я в мире знаю только 
цельность»), своего рода «ядро», в котором неразделимы причины и следствия. Всё, что совершается в этом «ядре», само для себя есть и причина, и цель. Именно так смотрит поэт на историю России. Петровская эпоха - это и следствие каких-то процессов, и причина того, что произошло в XX веке. Большевистская эпоха - это следствие, но она содержит в себе и цель (вот она, телеологичность) - возрождение России, обретение «поруганного храма», ибо это неизбежно. Да, приход большевиков к власти ознаменовал царство антихриста... Но говорит же Господь в главе «Левиафан» книги «Путями Каина», призывая к приятию такого мира: «Сих косных тел алкание и злоба / Лишь первый шаг к пожарищам любви. / Я сам сошел в тебя, как в недра гроба, / Я сам томлюсь огнем в твоей крови. / Как я тебя - так ты взыскуешь землю. / Сгорая - жги! / Замкнутый в гроб - живи!» (Волошин 2004. 59).

Волошину как философу не хватает того, что связано с Россией и её историей. Его интересует человечество как таковое и даже нечто, ему предшествующее. В первой главе «Мятеж» («Путями Каина») даётся оригинальная концепция становления мироздания путём мятежа. По Волошину, «В начале был мятеж, / Мятеж был против Бога / И Бог был мятежом. / И все, что есть, началось чрез мятеж» (Волошин 2004. 7). По сути, речь идет о мятеже против себя самого в доказательство и обеспечение своего бытия. «И всё, что есть, началось чрез мятеж»: согласно «Диалектике мифа» А.Ф. Лосева, для того, чтобы «вывести это всё, надо его чему-то противопоставить... надо его чем-то отрицать...», и так как «никого и ничего нет кроме этого всего, то... всё будет само противополагать себя себе же» (Лосев 1991. 178). Это равновесие-противоречие и является источником существования мира, его способом и формой. «Бог был окружностью, / А центром Дьявол, / Распяленный в глубинах вещества» (Волошин 2004. 47).

Бог-окружность... Волошин, по сути дела, опираясь на древних философов, воссоздаёт картину античного космоса. Ведь ещё Ксенофан утверждал, что 
существо божье шарообразно. Парменид считал небо самым точным из встречающихся шаров, отмечая, что, наподобие Земли и Вселенной, Бог неподвижен, конечен и имеет форму шара. Для Волошина же главное - двоица как материальный и духовный принцип миростроительства, двоица как равновесие. Бог - дьявол, два демона, строителя-держателя вселенной, две дуги собора, упавшие друг на друга и тем самым образовавшие несгибаемый свод. И, наконец, «смерть и рожденье - вся нить бытия» (Волошин 2003. 39), в другом месте: «смерть и воскресенье - творящий ритм мятежного огня» (Волошин 2004. 7). Человек «утверждает Бога мятежом, / Творит неверьем, строит отрицаньем, / Он зодчий, / И его ваяло - смерть...» (Волошин 2004. 8).

В основе волошинской космософии - гармония равновесий, «зеркальный бред взаимоотражений». «Мир осязаемых и стойких равновесий», возникший из «вихрей и противоборств» (Волошин 2004, 7) обречённый на распад, но и сохраняющий надежду на спасение, восстановление изначальной гармонии. Эта система равновесий (равновесие противоположностей), включающих в себя череду взаимопритяжений и отталкиваний, проявляется в космогонических фантазиях и утверждается в историософском восприятии современности. В начале главы «Космос» даётся поэтическая концепция сотворения мира по Каббале (книга Зогар), и описано божественное творчество: «Десница подняла материки, / А левая распределила воды, / От чресл размножилась земная тварь, / От жил - растения, от кости — камень...» (Волошин 2004, 44). Здесь же упоминаются «двойники - небесный и земной», которые «Соприкоснулись влажными ступнями. / Господь дохнул на преисподний лик, / И нижний оборотень стал Адамом. / Адам был миром, / Мир же был Адам...» (Волошин 2004. 44).

Не вдаваясь в историю происхождения этих образов, заметим, что здесь налицо единство, превратившееся в двоицу. Если число 1 (монада) традиционно является выражением такой гармонической целостности, как Бог 
или космос, то 2 (двоица) чаще всего представляет собой две противоположности, антиномию, нередко таящую в себе гибель. Однако у Волошина подразумевается равновесие противоположностей, единство противопоставления взаимодополняющих частей монады.

Эволюцию человечества поэт воспринимает как бунт против равновесия вещей и столкновение контрастных начал. Зло необходимо хотя бы как ступень к добру, достигаемому через бунт против зла. При этом «благоразумный» возвращается в стадо; «мятежник» стремится пересоздать мир и себя, но застревает в «капканах равновесья». К тому же он попадает в плен к собственным иллюзиям. В бунте против материи человеку начинает казаться, что он подчинил себе духов природы, однако в действительности он сам попал в подчинение эльфам и кобольдам, ундинам и саламандрам, освободив «силы / Извечных равновесий вещества». И с этого момента «Бесы пустынь, самумов, ураганов / Ликуют в вихрях взрывов, / Дремлют в минах / И сотрясают моторы машин...» («Магия») (Волошин 2004. 14).

Революция «есть... нарушение того высшего религиозного принципа жизни, который составляет основу религиозной жизни как индивидуальной, так и общественной, т. е. её органическое единство» (Из глубины 1991. 10), писал философ С.А. Аскольдов. По его мнению, революция - это власть множественности над государственным единством, в какой бы форме оно ни выражалось. У Волошина эта множественность, «расплавляющая спайки целого», - множественность бесов. Исключительной, нерушимой целостностью представляется художнику в это страшное время лишь «меч молитв», означающий крепость целительного слова: «Когда же в мир пришли иные силы / И вновь преобразили человека, - / Меч не погиб, но расщепился в дух...» («Меч») (Волошин 2004. 21).

Утверждая свой «единственный мыслимый идеал», «Град Божий», «находящийся... за гранью времён», поэт даёт повод задуматься о постоянном, 
как говорил Н.А. Бердяев, «противодействии вечного во времени, постоянном усилии вечных начал свершить победу вечности» (Бердяев 1990. 53).

\section{Заключение}

Весь волошинский поэтический строй воспринимается, как уже говорилось, сквозь призму равновесия противоположностей, весь мир и его эволюция есть сложная система противоположностей, их борьбы и их конечного равновесия. Нарушение этого принципа, когда те или иные силы разрушают изначальную и сущностную гармонию, равновесие противоположных начал, ведёт к катастрофе, что и подтвердили революционные события в России. В своей историософской концепции М. Волошин в значительной степени отталкивается от теории О. Шпенглера («Закат Европы»), основная мысль которой - безысходное круговращение истории и неминуемая гибель культуры под спудом механистическопотребительской цивилизации. Поэт считал, что в мире в целом идёт непрерывный распад материи, обрекающий его на полное исчезновение, и высказывает гениальное предположение, что история будущего пройдёт под знаком «интраатомной» энергии. Разрушительные тенденции в мире, стремящиеся нарушить с трудом удерживаемое равновесие, огромны. Спасти человечество и этот «гибнущий мир распадающегося вещества» может только противоположный поток, «зиждительный поток творящей энергии», горение человеческой любви, которая способна возродить утраченную гармонию между противоположными началами.

\section{Литература}

1- Бердяев Н.А. (1990). Смысл истории. Москва: Изд-во «Мысль».

2- Волошин М. (1988). Лики творчества. Ленинград: Изд-во «Наука».

3- Волошин М.А.(1992). Россия распятая: Сборник статей и стихов. Москва: Изд-во «ПАН». 
4- Волошин М.А. (2003). Собрание сочинений. Том 1. Москва: Изд-во «Эллис Лак».

5- Волошин М.А. (2004). Собрание сочинений. Том 2. Москва: Изд-во «Эллис Лак».

6- Воспоминания о Максимилиане Волошине (1990). Москва: Изд-во «Советский писатель».

7- Вышеславцев Б.П. (б.г.). Бессмертие, перевоплощение и воскресение // Переселение душ: проблема бессмертия в оккультизме и христианстве. Paris: YMCA-PRESS.

8- Из глубины: Сборник статей о русской революции (1991). Москва: Изд-во «Правда».

9- Лосев А.Ф. (1991). Философия. Мифология. Культура. Москва: Изд-во «Политиздат».

\section{Bibliography}

1- Berdjaev N.A. (1990). Smysl istorii. Moskva: Izd-vo «Mysl'».

2- Voloshin M. (1988). Liki tvorchestva. Leningrad: Izd-vo «Nauka».

3- Voloshin M.A.(1992). Rossija raspjataja: Sbornik statej i stihov. Moskva: Izd-vo «PAN».

4- Voloshin M.A. (2003). Sobranie sochinenij. Tom 1. Moskva: Izd-vo «Jellis Lak».

5- Voloshin M.A. (2004). Sobranie sochinenij. Tom 2. Moskva: Izd-vo «Jellis Lak».

6- Vospominanija o Maksimiliane Voloshine (1990). Moskva: Izd-vo «Sovetskij pisatel'».

7- Vysheslavcev B.P. (b.g.). Bessmertie, perevoploshhenie i voskresenie // Pereselenie dush: problema bessmertija v okkul'tizme i hristianstve. Paris: YMCA-PRESS.

8- Iz glubiny: Sbornik statej o russkoj revoljucii (1991). Moskva: Izd-vo «Pravda».

9- Losev A.F. (1991). Filosofija. Mifologija. Kul'tura. Moskva: Izd-vo «Politizdat».

\section{HOW TO CITE THIS ARTICLE}

Пинаев C. M. (2020). Balance of Oppositions as a Philosophical Base of Maximilian Voloshin's Life and Creativity. Issledovatel'skiy Zhurnal Russkogo Yazyka I Literatury, 8(1), 35-47.

DOI: $10.29252 /$ iarll.15.35

URL: http://www.journaliarll.ir/index.php/iarll/article/view/107 


\section{نظام تعادل به عنوان اساس و پايهُ فلسفى زندگى و آثار ادبى ماكسيميليان و الوشين}

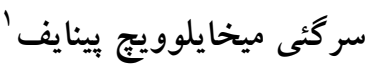

استاد، دانشخاه دوستى ملل روسيه،

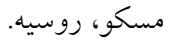

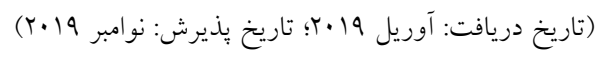

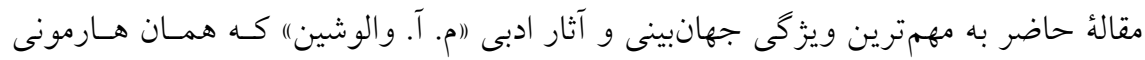

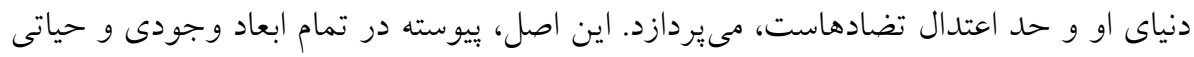

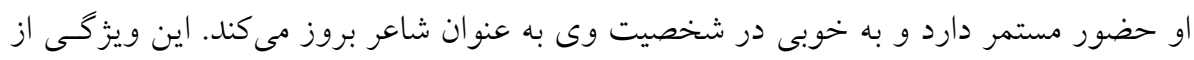

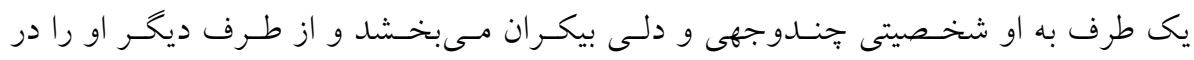

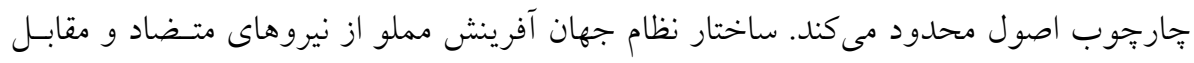

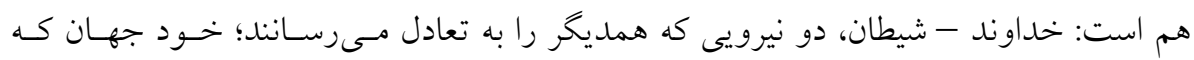

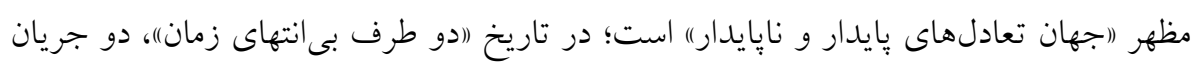

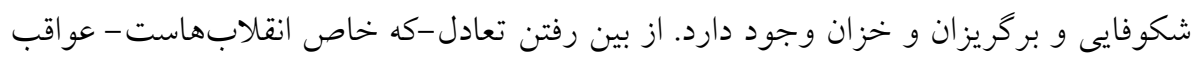

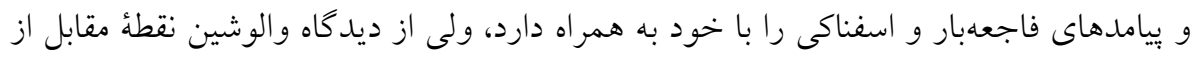

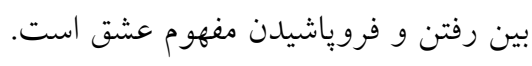
وازگًان كليدى: والوشين، جهانبينى، هارمونى، تعادل، تضادها و اضداد، انقلاب. 